\title{
Cloning and Analysis of PCR-generated DNA Fragments
}

\author{
Gina L. Costa, Albert Grafsky, and Michael P. Weiner
}

Stratagene Cloning Systems, La Jolla, California 92037

\begin{abstract}
Methods are presented for the improved yield and analysis of bluntended cloning of PCR-generated DNA fragments. We show that Pfu DNA polymerase polishing of Taq DNA polymerase-generated fragments increases the yield and efficiency of cloning. Using a triple primer set consisting of two outside, asymmetrically distanced primers and one fragment-specific primer, both the presence and orientation of cloned inserts can be determined. Application of these methods allows the generation and cloning of a fragment in 1 day and the analysis of putative clones the next, thereby saving a substantial amount of both time and effort.
\end{abstract}

$\mathbf{F}_{\mathrm{i},}$ the routine cloning of PCR-generated DNA fragments (Figs. 1 and 2). These include the incorporation of restriction enzyme sites into deoxyoligonucleotide primers; ${ }^{(1)}$ T/A cloning, which relies on the terminal deoxynucleotide transferase activity of some of the polymerases used in PCR; ${ }^{(2,3)}$ uracil DNA-glycosylase (UDG) treatment of uracil-containing deoxyoligonucleotide primers; ${ }^{(4,5)}$ ligase-independent cloning (LIC), which uses the $3^{\prime} \rightarrow 5^{\prime}$ proofreading activity of some polymerases; ${ }^{(6)}$ and blunt-ended cloning. ${ }^{(7)}$

Restriction enzyme site incorporation is probably the most widely used method for cloning PCR fragments but also one of the most problematic. The main advantage of this method is that the fragment can be cloned into a vector construct at precisely the place it is desired. Any site not contained within the fragment itself can be incorporated into the primer design. Cloned insert directionality is made possible through the presence of different restriction target sites on each primer.

There are, however, two major drawbacks with this method. The first is that extra bases, which result in additional expense, must be included in the design of the primers. This is because most restriction enzymes need a stretch of DNA that is longer than their target sequence to bind to and cleave the DNA. For example, the restriction enzyme NotI needs at least 10 bases of double-stranded DNA, (5'-NNGCGGCCGCNN-3') to restrict at its recognition site $\left(5^{\prime}\right.$-GCGGCCGC- $\left.3^{\prime}\right)$. To achieve efficient cleavage, it is recommended that three $\mathrm{G} / \mathrm{C}$ base pairs be added $5^{\prime}$ to the incorporated restriction target site in the primer to act as an annealing clamp. Tests to determine the parameters associated with efficient restriction digestion either require radioactivity or are cumbersome to perform. In most cases, until clones are analyzed by DNA sequence analysis it cannot be ascertained whether the method has worked. The second drawback to restriction enzyme site incorporation is the inability to achieve efficient cleavage. Inhibition of digestion can occur because of the presence of incompatible polymerase buffers and a molar excess of primers left over from the PCR reaction. Some restriction enzymes are inhibited by the half-sites found on primers. Therefore, a cleanup step is often needed to remove contaminating antagonists. Some reports in the literature also suggest that a proteinase $\mathrm{K}$ and phenol/chloroform extraction may be required for some restriction enzymes. ${ }^{(8)}$

The T/A cloning methods were developed from an observation by Clark et al. ${ }^{(9,10)}$ that some DNA polymerases and reverse transcriptases contain a terminal deoxynucleotidyl transferase (TdT) activity that results in the addition of one or more nucleotides at the 3 ' ends of blunt-ended DNA molecules. $\mathrm{Hu}^{(11)} \mathrm{ex}-$ tended these studies to show that the 3 '-end nucleotide extension by DNA polymerases is both nucleotide and polymerase specific. For example, Taq DNA polymerase extends a single $\mathrm{G}$ nucleotide if the $3^{\prime}$ nucleotide on the fragment is a $G$ but adds an $A$ if the $3^{\prime}$ nucleotide is a C. A $3^{\prime} \mathrm{T}$ nucleotide results in the nonaddition of a $T$ and an addition of an A. Fragments that end with an A had an additional $A$ added to the 3 ' ends with extremely low efficiency. Of the examined polymerases that were found to have the TdT activity (T7, modified T7, Taq, Vent, Klenow, and Escherichia coli Pol I polymerases), there ap- 
A Restriction enzyme site incorporation

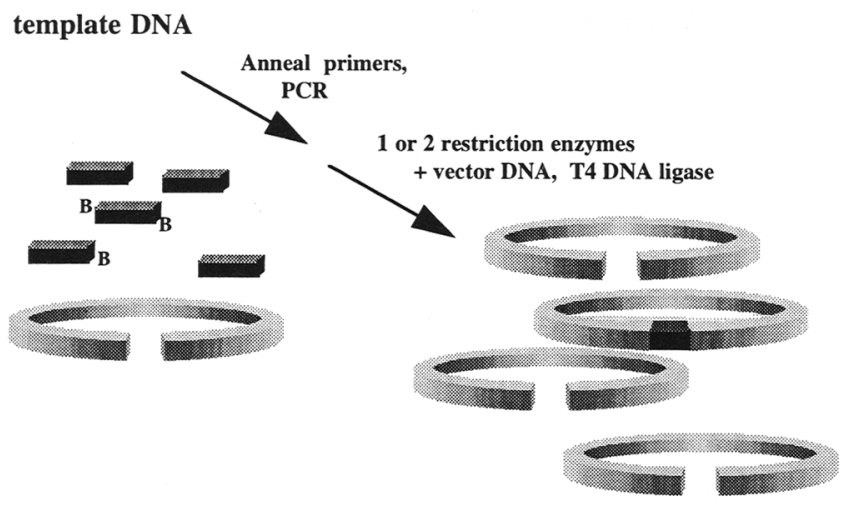

C UDG cloning

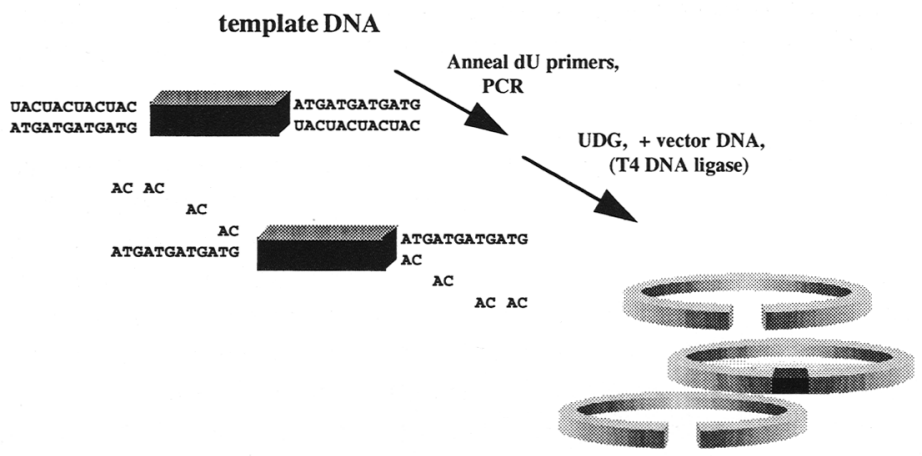

B T/A cloning
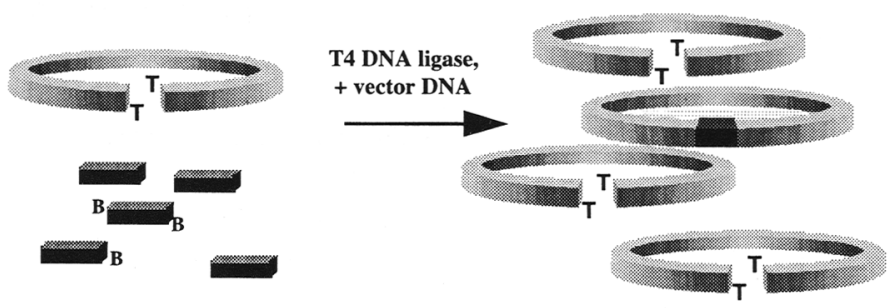

D Ligase independent cloning

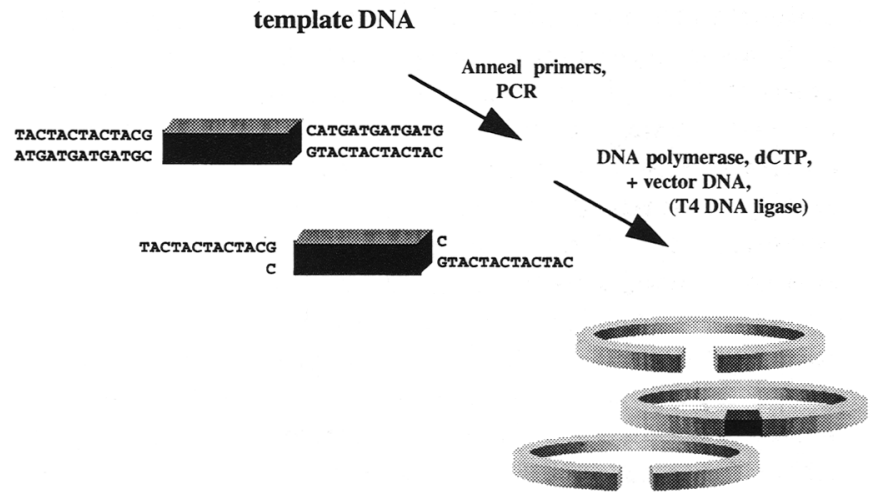

FIGURE 1 General methods used in PCR cloning. $(A)$ Restriction site incorporation; $(B)$ T/A; $(C)$ LIC; and $(D)$ UDG PCR cloning methods. See text for details.

pears to be no consistent patterns for which bases were added. Therefore, it cannot be assumed that all DNA polymerases create blunt-ended fragments. Fortunately, T4 and Pfu DNA polymerases were found not exhibit any DNA extendase or TdT activity and can be used to create blunt-ended fragments.

In the T/A method, a plasmid vector is prepared such that a single $T$ residue is extended at the $3^{\prime}$ ends. The vector can be enzymatically processed using (1) a pair of inverted restriction enzyme sites $(X c m I, H p h \mathrm{I})$ to leave single $3^{\prime}$ overhangs, (2) TdT and a dideoxythymidine triphosphate (ddTTP), (3) modified T7 DNA polymerase, dTTP, and a linearized vector, or (4) DNA ligase and linkers. The prepared vector is then added to a ligation solution containing appropriate buffers and a dilution of the PCR fragment. No post-PCR purification or additional bases are needed because this method is based on the assumption that a portion of the PCR-generated fragments will contain 3 '-end adenosine residues created by the DNA polymerase. Extended ligation times are necessary for T/A cloning because of the inefficiency of T4 DNA ligase to act on single-base $3^{\prime}$ overhangs.

Because of the extendase activity associated with the DNA polymerases used in thermal amplification, care must be exercised when designing the $5^{\prime}$ ends of PCR primers for the T/A cloning method to ensure that the optimal base is retained at the 3 ' end for the particular fragment-generating polymerase used. The T/A cloning method will not be useful with the newer proofreading and blunt end-generating DNA polymerases that are gaining more widespread acceptance for PCR. At present, the T/A methods have been developed solely as a bidirectional cloning method.

The UDG and LIC methods create extended (12-base) overhangs in the PCR fragment using uracil DNA glycosylase (in the UDG method) to create $3^{\prime}$ overhangs, and the proofreading activity of a DNA polymerase (generally T4 DNA polymerase, in the LIC method) to create 5 ' overhangs. These overhangs can then be used to anneal to complementary overhangs created in modified plasmid vectors created in a similar manner. The advantages to these methods are the high efficiencies and yields obtained in cloning. The main disadvantages are the difficulty in vector preparation that necessitates the use of specialized vectors and the added expense of 24 extra bases to the PCR primer set, which can increase the cost of PCR cloning by $\geqslant 30 \%$. Also, the 12-base single-stranded ends are extremely sensitive to singlestranded nucleases. Bidirectional and directional methods are available for both LIC and UDG methods, although it is generally better to use noncomplementary ends on the vector (in the direc- 
A
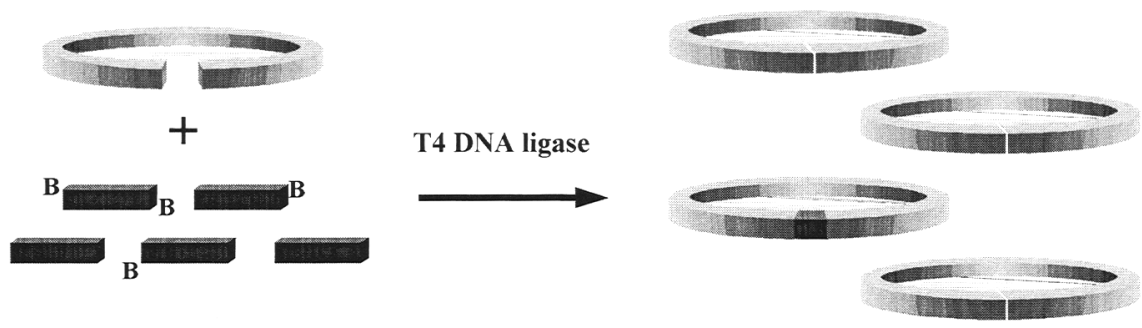

B

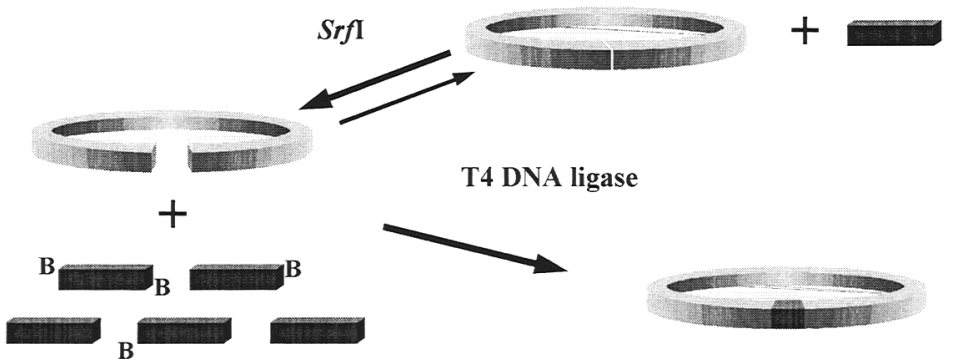

FIGURE 2 Blunt-ended and pCR-Script cloning methods. $(A)$ Methods for standard blunt-ended cloning include incubation of the PCR product with predigested vector DNA and T4 DNA ligase. $(B)$ More efficient methods include the addition of the restriction enzyme (in this example, $S r f l$ endonuclease) to regenerate the linearized vector from the self-ligated vector during the ligation reaction.

tional procedures) to prevent high background attributable to nonrecombinant vector reannealing. Although speed of the process as a result of the absence of a ligation step is often cited as an advantage of the LIC and UDG methods, in truth the reactions require an annealing step; so these methods take about the same amount of time as the blunt-ended cloning procedures described below.

Blunt-ended cloning procedures capture blunted PCR fragments for bidirectional insertion. As with the T/A system, blunt-ended cloning does not require the addition of extra bases to the primer sets, thereby allowing preexisting primers to be used to generate and clone a DNA fragment. Cloning efficiencies of polymerase-generated PCR products can be increased by using T4 or Pfu DNA polymerase to polish or complete unfinished fragments as well as remove any added extended nucleotides. In general, T4 DNA ligase concentrations can be optimized to achieve $>70 \%$ completion of clonal insertion in 1-2 hr at room temperature.

Unfortunately, blunt-ended cloning is an inefficient method, with recombinant insertion generally accounting for $<10 \%$ of all transformants. ${ }^{(12)}$ To alleviate this drawback, phenotypic selection [e.g., disruption of the $\beta$-galactosidase ( $\beta-\mathrm{Gal}$ ) gene] is often used to detect recombinants (white colonies on X-galcontaining agar plates) from nonrecombinants (blue colonies on the above plating medium). Further increases in efficiency are achieved by the inclusion of a restriction enzyme in the ligation reaction.

The remaining portion of this paper describes methods that we have developed and invented to increase the cloning efficiency and facilitate both directional and bidirectional cloning of blunt-ended DNA fragments.

\section{MATERIAL AND METHODS}

\section{Materials}

Taq DNA polymerase was purchased from Perkin-Elmer Cetus. All other reagents, including $P f u$, and Klenow polymerases, T4 DNA ligase, SrfI restriction endonuclease, reaction buffers, rATP, dNTP, X-gal, and IPTG mixtures were obtained from Stratagene (La Jolla, CA). Polydeoxynucleotide primers were synthesized at Stratagene on an Applied Biosystems 380 oligonucleotide synthesizer. Competent E. coli XL1 Blue MRF' Kan and SURE cells were obtained from Stratagene and used according to supplied protocols. Culture medium used was $2 \times$ YT with added antibiotic (either chloramphenicol, $30 \mu \mathrm{g} / \mathrm{ml}$; or ampicillin/ methicillin at $80 / 20 \mu \mathrm{g} / \mathrm{ml}$ ). Plating medium contained an additional $0.75 \%$ agar. Colonies were scored for $\beta$-gal phenotype on LB plates containing $40 \mu \mathrm{g} / \mathrm{ml}$ of X-gal and 0.5 mM IPTG.

\section{PCR Primer Design}

For the bidirectional PCR cloning experiments four sets (A, C, G, and T) of 23mer oligonucleotides to the chloramphenicol gene from $\mathrm{pBC} \mathrm{SK}(+)$ were synthesized: (1) 5'-A set, 5' -ACTGTGACGGAAGATCACTTCGC-3' and 5'-ACTCCACGGGGAGAGCCTGAGCA-3'; (2) $5^{\prime}$-C set, $5^{\prime}$-CCTGTGACGGAAGATCACTTCGC-3' and 5'-CCTCCACGGGGAGAGCCTGAGCA-3'; (3) 5'-G set, 5'-GCTGTGACGGAAGATCACTTCGC-3' and 5'-GCTCCACGGGGAGAGCCTGAGCA-3'; and (4) 5'-T set, 5'-TCTGTGACGGAAGATCACTTCGC-3' and 5'-TCTCCACGGGGAGAGCCTGAGCA-3'. Actual genetic homology to the cam Rene is exhibited by the $5^{\prime} \mathrm{C}$ primer set. For the directional PCR cloning experiments the 23 -mer $5^{\prime} \mathrm{C}$ primer set was used and further modified to include a 5' terminal phosphate on the upstream oligonucleotide: 5'-pCCTGTGACGGAAGATCACTTCGC- $3^{\prime}$.

For recombinant insert analysis two 30-mer oligonucleotides were synthesized, which confer genetic homology with all pBluescript-derived vectors.

\section{PCR}

A typical PCR contained (per $100 \mu \mathrm{l}) 1 \mu \mathrm{g}$ of each primer, $250 \mathrm{~nm}$ each dNTP, 10$100 \mathrm{ng}$ of template DNA, $1 \times$ reaction buffer, and 4 units of Taq DNA polymerase. For colony PCR, a final volume of $1 \%$ Tween 20 was added to the reaction mixture. PCR cycling conditions consisted of a single cycle hot start of 4 $\min$ at $94^{\circ} \mathrm{C}, 2 \mathrm{~min}$ at $50^{\circ} \mathrm{C}$, and $2 \mathrm{~min}$ at $72^{\circ} \mathrm{C}$, followed by 30 cycles of $1 \mathrm{~min}$ at $94^{\circ} \mathrm{C}, 2 \mathrm{~min}$ at $54^{\circ} \mathrm{C}$, and $1 \mathrm{~min}$ at $72^{\circ} \mathrm{C}$. The reactions were then incubated for an additional $10 \mathrm{~min}$ at $72^{\circ} \mathrm{C}$ before placement at $6^{\circ} \mathrm{C}$. For most experiments the PCR fragments were used without any further post-PCR production purification. In experiments where purification 
was desired or necessary, the DNA was salted out of solution with $10 \%$ volumeadded lithium chloride ( $1 \mathrm{M}$ final concentration from a $10 \mathrm{M} \mathrm{LiCl}$ stock) and 2.5 volumes ice-cold absolute ethanol. The DNA was pelleted at $14,000 \mathrm{~g}$ for 10 min, dried in vacuo, and resuspended in TE buffer [ $5 \mathrm{~mm}$ Tris ( $\mathrm{pH} 7.5$ ), $0.1 \mathrm{~mm}$ EDTA].

\section{Colony PCR}

Colony PCR was performed directly from transformation plates by stabbing a single colony with a toothpick, inoculating the adhered cells directly into a PCR cocktail containing $1 \%$ Tween 20 , and using the cycling parameters described in the previous section.

\section{End-polishing Reactions}

Precipitated PCR-generated fragments were adjusted to $1 \mu \mathrm{g} / \mu \mathrm{l}$ in $1 \times$ buffer (either Klenow, T4, or Pfu buffer), $100 \mathrm{~nm}$ dNTP, and 5 units of polymerase enzyme. Reactions were incubated for 30 min at $37^{\circ} \mathrm{C}$ for $\mathrm{T} 7$ and Klenow DNA polymerases, and $72^{\circ} \mathrm{C}$ for $P f u$ DNA polymerase.

\section{Ligation Reactions and $E$. coll Transformations}

Ligations were performed at room temperature by incubating, in a $10-\mu l$ reaction solution, $2 \mu \mathrm{l}$ of the PCR reaction, $0.5 \mathrm{~mm}$ (final) rATP, $1 \mu \mathrm{l}$ of $10 \times$ universal buffer, $10 \mathrm{ng}$ of predigested vector, 4 units of T4 DNA ligase, and, when specified, $\geqslant 15$ units of SrfI restriction endonuclease.

Bacterial $E$. coli were transformed according to the Stratagene protocols supplied with the supercompetent cells (XL1 Blue MRF' Kan).

\section{RESULTS AND DISCUSSION}

\section{Blunt-ended and pCR-Script Cloning}

Blunt-ended PCR cloning is most easily achieved by incubating an aliquot of the PCR fragment in the presence of predigested vector DNA in a solution containing the components needed for ligation (buffers, rATP, and enzyme; see Fig. 2). After a suitable incubation period, the ligation reaction is transformed into the appropriate cell line and subsequently analyzed for the presence of the insert.
TABLE 1 Cloning Efficiencies of Blunt-ended, pCR-Script and pCR-Script Direct Cloning

\begin{tabular}{|c|c|c|c|c|c|}
\hline \multirow[b]{2}{*}{$5^{\prime}$ Base pair ${ }^{a}$} & \multirow[b]{2}{*}{$\mathrm{CFU}^{\mathrm{b}}$} & \multicolumn{2}{|c|}{ Percent $^{c}$} & \multirow[b]{2}{*}{ True positives $^{d}$} & \multirow{2}{*}{$\begin{array}{l}\text { Percent } \\
\text { desired orientation }\end{array}$} \\
\hline & & $\beta-\mathrm{gal}^{+}$ & $\beta-\mathrm{gal}^{-}$ & & \\
\hline \multicolumn{6}{|c|}{ Blunt-ended cloning } \\
\hline A & 1240 & 84 & 16 & 100 & \\
\hline$C^{f}$ & 1348 & 89 & 11 & 100 & $50^{8}$ \\
\hline G & 1672 & 90 & 10 & 100 & \\
\hline $\mathrm{T}$ & 1232 & 83 & 17 & 100 & \\
\hline \multicolumn{6}{|c|}{ pCR-Script cloning } \\
\hline A & 424 & 10 & 90 & 100 & \\
\hline $\mathrm{C}$ & 99 & 11 & 89 & 97 & 50 \\
\hline G & 216 & 7 & 93 & 100 & \\
\hline $\mathrm{T}$ & 300 & 17 & 83 & 100 & \\
\hline \multicolumn{6}{|c|}{ pCR-Script direct cloning } \\
\hline $\mathrm{C}$ & 233 & 70 & 30 & 87 & 92 \\
\hline $\mathrm{C}$ & 202 & 49 & 51 & 97 & 82 \\
\hline $\mathrm{C}$ & 97 & 48 & 52 & 92 & 86 \\
\hline $\mathrm{C}$ & 315 & 36 & 64 & 100 & 85 \\
\hline
\end{tabular}

${ }^{\mathrm{a}} 5^{\prime}$ Base at both ends of the PCR fragment. Insert genes were derived from PCR of the cam Renes using primers described in text.

${ }^{b}$ (CFU) Colony-forming units examined.

${ }^{c}$ Percent of colonies expressing $\beta$-gal $\left({ }^{+}\right)$or not expressing activity $\left(^{-}\right)$.

${ }^{\mathrm{d}}$ Percent of $\beta-\mathrm{gal}^{-}, \mathrm{Amp}^{\mathrm{R}}$ colonies expressing $\mathrm{Cam}^{\mathrm{R}}$,

'Orientation of the cloned insert with respect to the plasmid multiple cloning site (see text for further details).

' 5 ' Base that confers genetic homology to cam $\mathrm{R}$ gene DNA template.

${ }^{8}$ The average desired orientation observed in bidirectional cloning experiments using the wildtype cam $\mathrm{R}$ gene sequence.

TABLE $23^{\prime}$-End Modification by DNA Polymerases

\begin{tabular}{|c|c|c|c|c|}
\hline \multirow[b]{2}{*}{ Polishing enzyme ${ }^{a}$} & \multirow[b]{2}{*}{$5^{\prime}$ nucleotide $^{b}$} & \multirow[b]{2}{*}{$3^{\prime}$-End modification ${ }^{c}$} & \multicolumn{2}{|c|}{ Recombinants $^{\mathrm{d}}$} \\
\hline & & & $\overline{\mathrm{CFU}^{\mathrm{e}}}$ & Efficiency $^{\mathrm{f}}(\%)$ \\
\hline \multirow[t]{4}{*}{ Taq DNA polymerase ${ }^{g}$} & $\mathrm{~A}$ & $-\mathrm{T},+\mathrm{A}$ & 158 & 4 \\
\hline & $\mathrm{C}$ & $+\mathrm{G}>+\mathrm{A}>>+\mathrm{C}$ & 89 & 10 \\
\hline & G & $+\mathrm{A}>+\mathrm{C}$ & 155 & $<1$ \\
\hline & $\mathrm{T}$ & $(+\mathrm{A})$ & 136 & 75 \\
\hline \multirow[t]{4}{*}{ Klenow fragment } & A & $+\mathrm{A}$ & 26 & 12 \\
\hline & $\mathrm{C}$ & $+C>>+G+A$ & 30 & $<3$ \\
\hline & G & $+\mathrm{A}>>+\mathrm{C}$ & 125 & 20 \\
\hline & $\mathrm{T}$ & $(+\mathrm{A})$ & 30 & 67 \\
\hline \multirow[t]{4}{*}{ T4 DNA polymerase } & $\mathrm{A}$ & blunt end & 216 & 89 \\
\hline & $\mathrm{C}$ & blunt end & 79 & 86 \\
\hline & G & blunt end & 54 & 96 \\
\hline & $\mathrm{T}$ & blunt end & 132 & 91 \\
\hline \multirow[t]{4}{*}{ Pfu DNA polymerase } & A & blunt end & 424 & 90 \\
\hline & $\mathrm{C}$ & blunt end & 116 & 93 \\
\hline & $\mathrm{G}$ & blunt end & 216 & 93 \\
\hline & $\mathrm{T}$ & blunt end & 383 & 89 \\
\hline
\end{tabular}

aDNA polymerase used to end-polish Taq-generated PCR products.

b5'-end nucleotide used in primer set.

' 3 '-end nucleotide extention (+) of DNA fragments by DNA polymerases (taken from Hu 1993). (11)

${ }^{\mathrm{d}}$ See legend to Fig. 1.

${ }^{\mathrm{e}}$ Colony-forming units; average total colonies per plate.

${ }^{\mathrm{f}}\left[\beta-\mathrm{Gal}^{-}\right.$(white) recombinants]/total CFUs.

${ }^{8}$ Untreated control (see Materials and Methods). 


\section{ResearchIIIII}
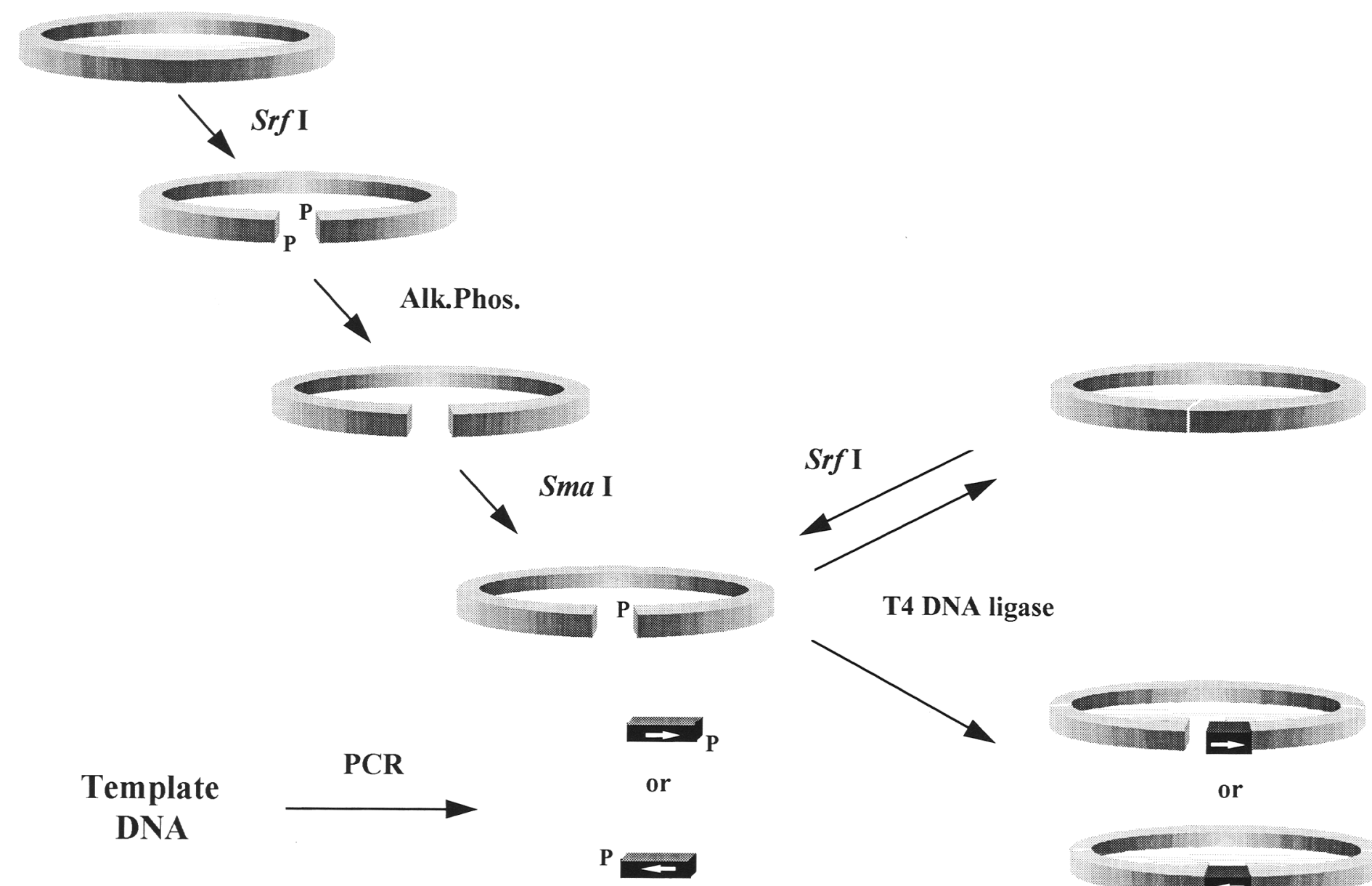

T4 DNA ligase
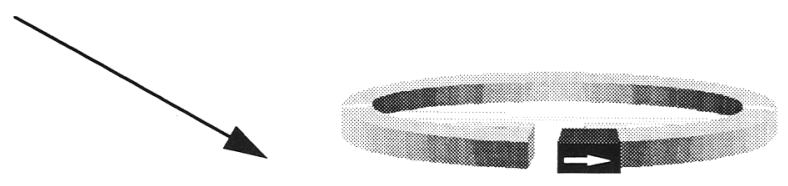

or

FICURE 3 Monophosphorylation and pCR-Script Direct cloning. The plasmid pCR-Script Direct is digested with the restriction enzyme Srfl, treated with alkaline phosphatase to remove the 5 '-phosphate groups, and digested with the restriction endonuclease SmaI. Ethanol precipitation was used to remove the small (15-bp) linker. The insert fragment was created using either a machine-synthesized 5 '-phosphorylated or kinase-treated primer. The monophosphorylated primer and vector are incubated in the presence of both Srfl and T4 DNA ligase. After room temperature incubation, the DNA was used to transform E. coli.

Because blunt-end ligation is inefficient, most of the transformed cells will contain vector DNA that has self-ligated. In unoptimized cloning procedures, this self-ligation represents $>90 \%$ of the total colonies (see Table 1). Therefore, in actual practice, a phenotypic selection is often used to aid in detecting transformants with the desired inserts. This selection is usually disruption of the $\beta$-gal gene which can be monitored on plating medium containing the chromogenic substrate X-gal.

To increase the efficiency of bluntended cloning of PCR fragments, Liu and Schwartz $^{(13)}$ found that a restriction enzyme added in a functional-unit excess relative to the ligase enzyme increases the efficiency of the ligation reaction. This simultaneous restriction digestion and ligation reaction results in an in- creased efficiency of blunt-ended cloning by two mechanisms. Primarily, as long as the PCR fragments do not create a restriction enzyme target site, the available linearized vector is removed from the overall reaction by recombinant insertion and an increased amount of linear vector is made available during the ligation reaction by restriction enzyme activity on self-ligated vector molecules. Second, because linear DNA molecules transform $E$. coli at a greatly reduced efficiency, they do not contribute to the number of colonies observed after transformation. This results in a reduced overall transformation efficiency, but because only the linearized, nonrecombinant plasmids are removed, the overall recombinant efficiency actually increases, allowing higher densities of cells to be plated.
In the pCR-Script methods that we have developed, we concentrated on the restriction enzyme SrfI for several reasons $^{(14)}$ (see Fig. 2). First, it has an octanucleotide recognition sequence $\left(5^{\prime}-\mathrm{GC}\right.$ CCGGGC-3') that is rare and would occur on average $1 / 65,000 \mathrm{bp}$ (because of the bias against CpG sequences in mammalian DNA, the actual occurrence is closer to $1 / 100,000 \mathrm{bp})$. Second, it is blunt-ended and contains an internal 6-base recognition site that can be recognized by another blunt-ended restriction enzyme (SmaI). This second reason will be more important for directional cloning as discussed below.

As shown in Table 1, addition of Srf restriction endonuclease to a ligation reaction allows for an overall fourfold increase in clonal efficiency, along with a greatly reduced background. 


\section{Effect of Polishing on Cloning Efficiency}

Depending on the polymerase used to generate the PCR fragment, there might be a need for "end polishing" to blunt the ends of the molecules that have been modified by terminal deoxynucleotidyl transferase. Such ends can be made blunt to increase blunt-ended cloning efficiency by polishing Taq-generated fragments with either T4 or Pfu DNA polymerase. ${ }^{(15)}$ We tested several enzymes to determine whether polishing helps or

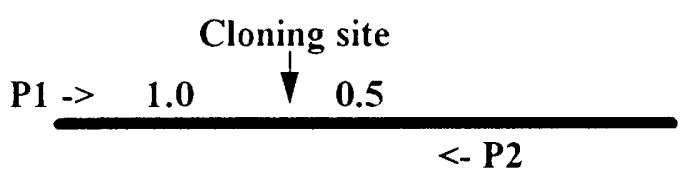

P1 ->

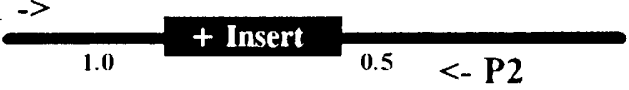

P1 ->

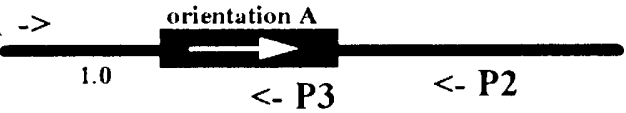

P1 ->

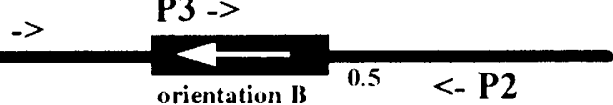

Example:

$1.2 \mathrm{~kb}$ Insert
A.

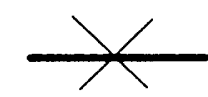

- Insert

B.

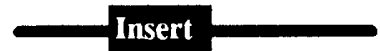

C.

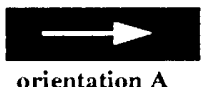

D.

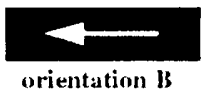

\section{PCR Products $(\mathrm{kb})$}

\section{5}

$1.5+$ Insert

$1.0+$ Insert

$0.5+$ Insert

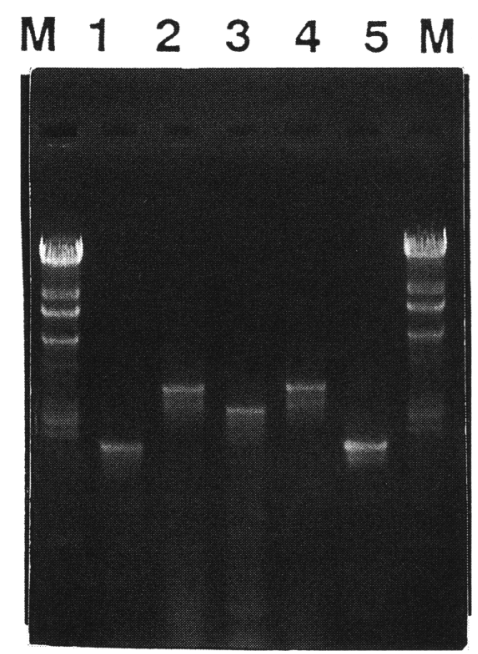

FIGURE 5 Gel analysis of recombinants using colony PCR. Using double and triple primer sets, colony PCR was conducted producing products that discern both the presence and the orientation of the cloned insert. (Lane M) Marker; $\lambda$ DNA/HindIII-digested; (lane 1) $\beta$-gal ${ }^{+}$(no insert), P1 + P2; (lane 2 ) $\beta$-gal ${ }^{-}$(+ insert/orientation A), P1 + P2; (lane 3) $\beta$-gal ${ }^{-}$ ( + insert/orientation A), P1 + P2 + P3; (lane 4) $\beta$-gal ${ }^{-}(+$insert/orientation B), P1 + P2; (lane 5) $\mathrm{B}_{-\mathrm{gal}^{-}}$(+ insert/orientation $\left.\mathrm{B}\right), \mathrm{P} 1+\mathrm{P} 2+$ P3. (For method, see Fig. 4.)

hinders the cloning efficiencies. PCR products of the chloramphenicol gene containing 3' pairs of either A, C, G, or T nucleotides were generated with $\mathrm{Taq}$ DNA polymerase. Subsequently, the PCR products were treated with Klenow, T4, or Pfu DNA polymerase to determine what effect polishing had on clonal efficiency. Appropriately, control reactions of unpolished (untreated) Taq-generated PCR products were used. The untreated and polished fragments were added to ligation reactions containing $10 \mathrm{ng}$ of vector, Srfl, T4 DNA ligase, rATP, and buffer. The results are shown in Table 2 and demonstrate that in specific cases polishing can increase overall recombinant cloning efficiencies.

FIGURE 4 Recombinant insert analysis. Schematic representation of PCR products generated using colony PCR to screen for recombinant clones. Verification of a cloned insert is achieved when PCR products using asymmetrically distanced primers (P1 and P2) are analyzed by gel electrophoresis. In a representative experiment where a $1.2-\mathrm{kb}$ insert is cloned into a plasmid DNA, recombinant colonies are picked directly from transformation plates and inoculated into PCR cocktails. Following thermal cycling, agarose gel analysis will yield PCR products indicative of insert presence and orientation. $(A)$ Nonrecombinants that do not contain a cloned insert will exhibit a 1.5-kb PCR product; and $(B)$ recombinants containing the 1.2-kb insert will exhibit a 2.7-kb PCR product. When PCR-generated fragments are used for cloning, directionality of the cloned insert can be achieved by adding a primer (P3) that was used to generate the cloned insert to the colony PCR cocktail. Recombinants will contain inserts that have been cloned in bidirectionally, and use of a third primer in the reaction mixture will confirm the orientation of the cloned fragment (orientation A or B). An example of recombinant screening of clones with a 1.2-kb insert by PCR in the presence of a third primer will reveal orientation of the cloned insert upon gel electrophoresis with either a $(C) 2.2-\mathrm{kb}$ or $(D)$ 1.7-kb PCR products.

\section{Monophosphorylation and PCR-Script Direct Cloning}

The methods described above result in bidirectional cloning of PCR fragments. To create a directional method that did not require the addition of extra bases to the primers, we relied on two facts known from previous experimentation. First, T4 DNA ligase requires a $5^{\prime}$ phos- 


\section{pCR Script}

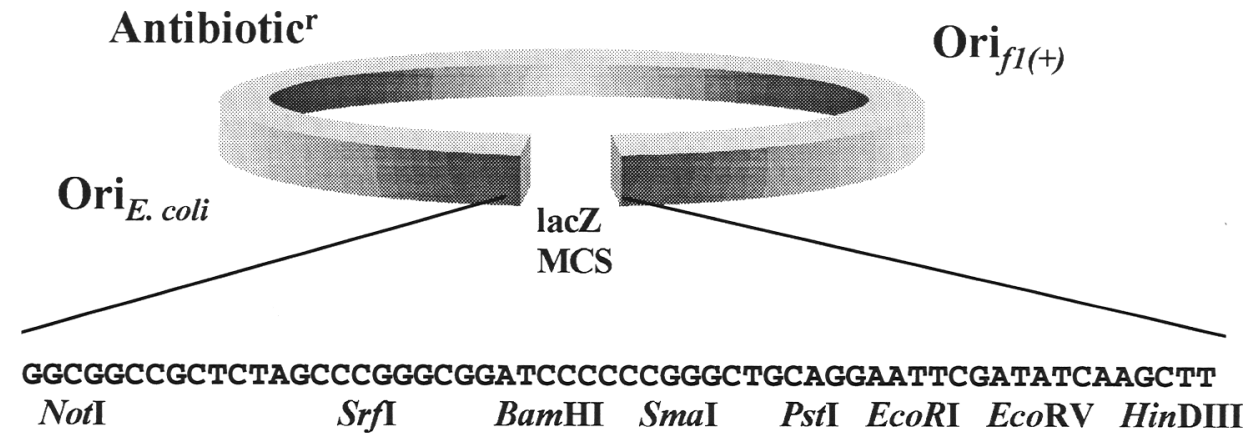

\section{pCR Script Direct}

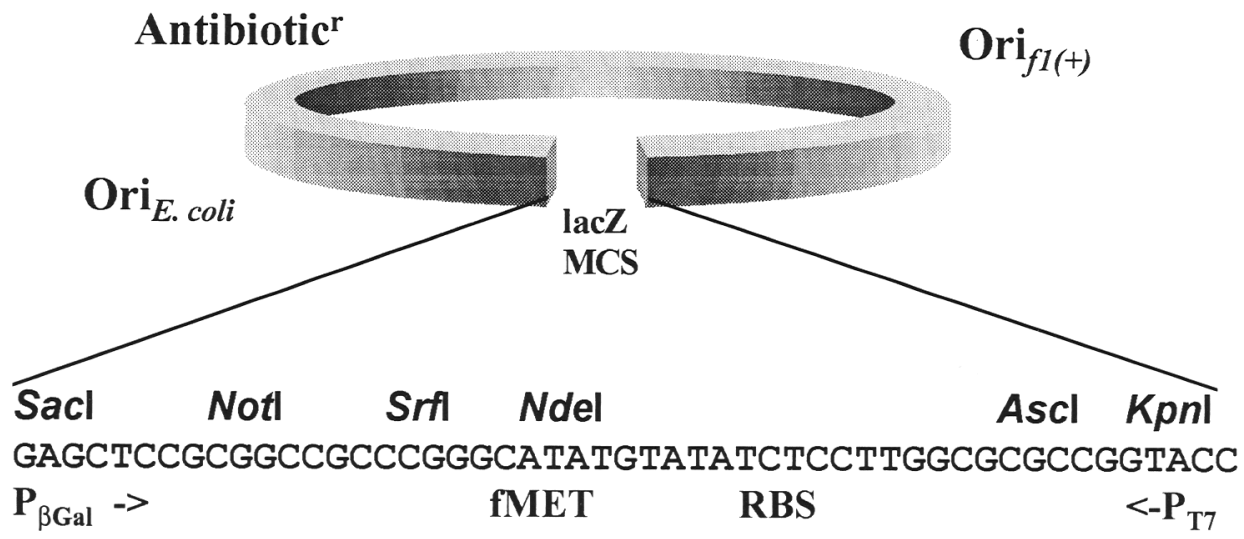

FIGURE 6 Vectors for bidirectional and directional cloning of PCR fragments. Several vectors have been developed for directional and bidirectional cloning. These include derivatives that encode either chloramphenicol or ampicillin resistance with modified multiple cloning sites optimized for specific cloning operations (e.g., general subcloning or protein expression).

phate and a $3^{\prime}$ hydroxyl group to efficiently ligate two strands of DNA together. Second, linear DNA transforms recBC-proficient hosts of $E$. coli at a greatly reduced efficiency (it is decreased by approximately four orders of magnitude). It was reasoned that directional cloning would be achieved if a monophosphorylated vector and a monophosphorylated insert were created. In the desired orientation, the ligation would then result in a nicked, circular, highly transformable molecule; and in the undesired, opposite orientation the ligation reaction would result in a linear molecule transformed with a drastically reduced efficiency.

Creation of a monophosphorylated vector can be achieved in several ways. We chose to enzymatically process a multiple cloning site (MCS) that was engineered to contain both a SrfI and a SmaI site. ${ }^{(16)}$ Digestion of this vector first with $S r f l$, dephosphorylation with alkaline phosphatase, and finally digestion with SmaI, resulted in the desired monophosphorylated vector (see Fig. 3). In the design of the MCS, we included a 3' C and $5^{\prime} \mathrm{T}$ at the SmaI site. The result is a SmaI site ( $5^{\prime}$-TCCCGGGC-3') containing a 3' SrfI half-site (5'- GGGC-3'). Because of this sequence, the enzymatically processed vector can be used in a pCR-Script type reaction whereby self-ligated vector is susceptible to restriction by the Srfl endonuclease present in the ligation reaction (see Fig. 3).

Insert monophosphorylation can be achieved by kinase-treating one primer prior to the PCR reaction or, preferably, by synthesizing a PCR primer with a $5^{\prime}$ phosphate group chemically attached. ${ }^{(17)}$

The actual PCR cloning with directionality occurs in a reaction identical to that described for pCR-Script. The results are shown in Table 1 . Using pCR-Script Direct cloning, $>90 \%$ of the $\beta$-gal ${ }^{-}$colonies contained the correct insert and $>90 \%$ of the cloned fragments were found to be cloned in the desired orientation. This is in contrast to the bidirectional method, where the fragments are cloned in both orientations at approximately the same frequency (see Table 1).

Regarding the sensitivity of the pCRScript cloning methods for the presence of any contaminating nucleases, removal of any base at the cloning site by a nuclease will result in the loss of the restriction target site. Religation by the DNA ligase will result in a transformable circular molecule that is resistant to SrfI. This false-positive molecule will be frameshifted, resulting in a nonfunctional $\beta$-gal gene, and will appear white on an X-gal-containing plate. Therefore, it is essential that the materials and enzymes used in both creating the monophosphorylated vector and in the ligation reaction be absolutely free of nuclease activity. For this reason we have found it necessary to either clone or repurify the enzymes used to generate the vector to ensure nuclease-free reagents. $^{(15)}$

\section{Recombinant Insert Analysis: Presence and Orientation}

Recombinant insert analysis of colonies resulting from transformed cells can be easily performed in 1 day using colony PCR. ${ }^{(18)}$ In this method primers flanking the insert can be used in a PCR containing a colony taken directly from the transformation plate. By using asymmetrically distanced primers, it is possible to discern both insert presence and orientation from the resulting PCR products following agarose gel analysis (see Fig. 4). Insert orientation can be determined 
by a restriction enzyme digestion of the PCR product and an a priori estimate to predict restriction fragment sizes. Alternatively, one can use a triple primer set containing the two asymmetric primers and an additional primer representing one from the primer set used to generate the original fragment. Agarose gel analysis of a PCR using such a triple primer set confirms both the presence and the orientation of the cloned insert without the need for further restriction enzyme digestion (see Fig. 5).

Alternatively, one could conduct routine plasmid DNA isolation after overnight incubation and determine both insert size and orientation following restriction enzyme digestion and agarose gel analysis.

\section{Vectors and Multiple Cloning Site Design}

Several vectors and derivatives have been created for PCR cloning. These include the standard pBluescript-type multiple cloning sites (pCR-Script Amp and pCR-Script Cam) and the abbreviated MCSs contained in the pCR-Script Direct plasmids $^{(19,20)}$ (see Fig. 6). The abbreviated MCSs allow the end user to incorporate common restriction enzyme sites into their PCR primer sets without the problem of having the same target sequence occurring in the plasmid vector.

We have observed that DNA sequences containing long G/C-rich regions are susceptible to point deletions that can destroy enzyme recognition sites and will appear as white (false-positive) transformant colonies. Such point mutations have been observed and have resulted in the elimination of the $\mathrm{Srfl}$ site within G/C-rich multiple cloning sites. Following DNA sequence analysis, it was found that these clones usually arise by the deletion of a single base at the $S r f$ site that is most likely attributable to either nuclease contamination during vector processing or spontaneous mutation during plasmid replication. The necessity of using highly purified enzymes for performing the directional and bidirectional cloning protocols as described cannot be overstated. Nuclease contamination must be determined and eliminated prior to performing the described experiments.

A high concentration of spontanteous single-point mutations in the plasmid
DNA used for pCR-Script and pCR-Script Direct is reduced by independent growth and isolation of a number of plasmid DNA preparations. The E. coli SUREgrown plasmid preparation with the lowest level of spontaneous Srfl site mutations (as detected by the pCR-Script assay) is chosen for further experiments. We are currently investigating the use of frameshifted double restriction sites that would allow less purified enzymes to function in pCR-Script and pCR-Script Direct-type reactions.

We have made both ampicillin and chloramphenicol derivatives of the pCRScript and pCR-Script Direct vectors (see Fig. 6). It is recommended that the chloramphenicol derivatives be used when subcloning DNA fragments generated from ampicillin-resistance-encoding plasmids. This ensures that recombinant colonies after $E$. coli transformation are not the result of parental plasmid transformation.

\section{ACKNOWLEDGMENTS}

We thank Tim Sanchez, Tim Simcox, Jon Goodwin, Ed Marsh, Brad Scott, Richard Fowler, and Mark Bergseid for production of competent $E$. coli cells and the cloning and purification of enzymes needed to create a workable pCR-Script Direct vector; and Steve Jurak for graphic assistance. G.L.C. thanks Dr. Keith Kretz for assistance in DNA sequencing. M.P.W. has benefited from discussions with John Bauer, and Drs. Jay Short, Mary Simcox, and Joe Sorge, Jr.

\section{REFERENCES}

1. Kaufman, D.L. and G.A. Evans. 1990. Restriction endonuclease cleavage at the termini of PCR products. BioTechniques 9: 304-306.

2. Holton, T.A. and M.W. Graham. 1990. A simple and efficient method for direct cloning of PCR products using ddT-tailed vectors. Nucleic Acids Res. 19: 1156.

3. Mead, D., N. Kristy, C. Hernstadt, R. Marcil, and L. Smith. 1991. A universal method for the direct cloning of PCR amplified nucleic acid. BioTechnology 9: 657663.

4. Longo, M.C., M.S. Berninger, and J.L. Hartley. 1990. Use of uracil DNA glycosylase to control carry-over contamination in polymerase chain reactions. Gene 93: 125-128.

5. Nisson, P., A. Rashtchian, and P. Watkins. 1991. Rapid and efficient cloning of AluPCR products using uracil DNA glycosylase. PCR Methods Applic. 1: 120-123.
6. Aslanidis, C. and P.J. de Jong. 1990. Ligation-independent cloning of PCR products (LIC-PCR). Nucleic Acids Res. 18: 6069-6074.

7. Scharf, S.J. 1990. Cloning with PCR. In PCR protocols (ed. M.A. Innis, D.H. Gelfand, J.J. Sninsky, and T.J. White), pp. 84 91. Academic Press, New York.

8. Crowe, J.S., H.J. Cooper, M.A. Smith, M.J. Sims, D. Parker, and D. Gewert. 1991. Improved cloning efficiency of polymerase chain reaction (PCR) products after proteinase $\mathrm{K}$ digestion. Nucleic Acids Res. 19: 184.

9. Clark, J.M., C.M. Joyce, and G.P. Beardsley. 1987. Novel blunt-end addition reactions catalyzed by DNA polymerase I of Escherichia coli. J. Mol. Biol. 198: 123-127.

10. Clark, J.M. 1988. Novel non-templated nucleotide addition reactions catalyzed by procaryotic and eucaryotic DNA polymerases. Nucleic Acids Res. 16: 9677-9686.

11. Hu, G. 1993. DNA polymerase-catalyzed addition of nontemplated extra nucleotides to the $3^{\prime}$ end of a DNA fragment. DNA Cell Biol. 12: 763-770.

12. Bauer, J., D. Deely, J. Braman, J. Viola, and M. Weiner. 1992. pCR-Script SK(+) cloning system: A simple and fast method for PCR cloning. Strategies Mole. Biol. 5: 6265.

13. Liu, Z. and L. Schwartz. 1992. An efficient method for blunt-end ligation of PCR products. BioTechniques 12: 28-30.

14. Simcox, T., S. Marsh, E. Gross, W. Lernhardt, S. Davis, and M. Simcox. 1991. Srfl, a new type-II restriction endonuclease that recognizes the octanucleotide sequence, 5'-GCCC/GGGC-3'. Gene 109: 121-123.

15. Costa, G. and M.P. Weiner. 1994. Protocols for cloning and analysis of bluntended PCR-generated DNA fragments. PCR Methods Applic. (Suppl.) 3: S95-S106.

16. Weiner, M.P. 1993. Directional cloning of blunt-ended PCR products. BioTechniques 15: 502-505.

17. Maniatis, T., E. Fritsch, and J. Sambrook. 1982. Molecular cloning: A laboratory manual. Cold Spring Harbor Laboratory, Cold Spring Harbor, New York.

18. Costa, G. and M. Weiner. 1994. ScreenTest: Recombinant screening for efficient PCR-mediated screening in one day. Strategies Mol. Biol. 7: 34-36.

19. Costa, G., T. Sanchez, and M. Weiner. 1994. pCR-Script Direct SK(+) vector for directional cloning of blunt-ended PCR products. Strategies Mol. Biol. 7: 5-7.

20. Costa, G., T. Sanchez, and M. Weiner. 1994. Improved PCR cloning. Strategies Mol. Biol. 7: 8 .

Received January 28, 1994; accepted in revised form April 18, 1994. 


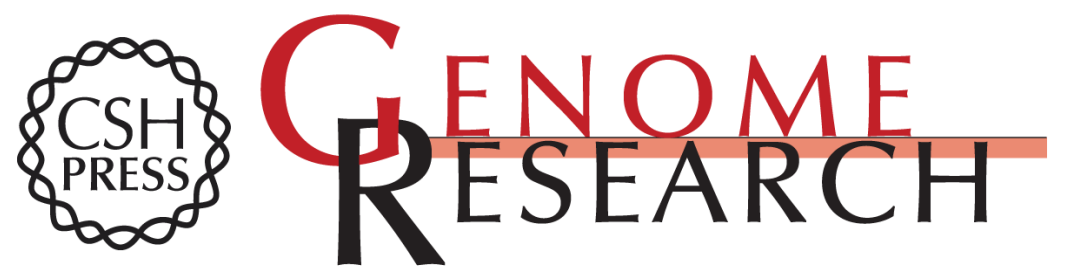

\section{Cloning and analysis of PCR-generated DNA fragments.}

G L Costa, A Grafsky and M P Weiner

Genome Res. 1994 3: 338-345

\section{License}

Email Alerting Service

Receive free email alerts when new articles cite this article - sign up in the box at the top right corner of the article or click here.

\section{Affordable, Accurate Sequencing.}

To subscribe to Genome Research go to: https://genome.cshlp.org/subscriptions 